\title{
Building Students' Personality for Employment Readiness through Soft-skills Training
}

DOI: https://doi.org/10.47175/rissj.v3i1.367

\section{Saranya $\mathbf{C}^{1}$ | Rajakumar Guduru ${ }^{2}$}

\author{
${ }^{1}$ Assistant Professor, \\ Department of English, Mepco \\ Schlenk Engineering College, \\ Sivakasi, Tamilnadu, India \\ ${ }^{2}$ Assistant Professor, School of \\ Humanities, Social Sciences \& \\ Management, Indian Institute \\ of Technology, Bhubaneswar, \\ Odisha, India \\ ${ }^{1}$ csaranya@mepcoeng.ac.in \\ 2rajakumarguduru@iitbbs.ac.in
}

\begin{abstract}
A winning personality is the physical attribute of a person and is considered as his or her success in personal, academic, and professional careers. However, in the ESL context, most engineering students seem to be unaware of the need for and importance of an appealing personality for achieving success in both personal and professional careers. Although students are given a short-term training in soft-skills by their respective college or institute, engineering students seem to lack aspects of a pleasing personality which helps them in job placements and later in the work environment. Therefore, the main aim of this study is to understand and build engineering students' personality traits such as enthusiasm, dependability, and teamwork for a successful career. For this purpose, to understand the students' personality types, 25 engineering students were administered a pre-test based on Carl Jung and Isabel Briggs Myers' typological approach to personality. Students were helped in building personality through the soft-skills training. The data was analyzed and interpreted both qualitatively and quantitatively. The results indicated that having a pleasing personality and exhibiting softskills enables in building students' individual personality for employment readiness. Implications were offered to students, placement trainers, and teachers. It is concluded that having a charming personality will support students in landing their desired jobs.

KEYWORDS

personality traits; employment readiness; soft-skills; employability skills; engineering students.
\end{abstract}

\section{INTRODUCTION}

The goal of language teaching, both at school as well as college/university level, is to not only promote learners' academic success but also support their social well-being. Education is essential to the development of an informed society, widening opportunities and giving people choices to experience the world. In the process, education imparts individuals with distinct personalities for creating new learning and renewed competencies for performing better in all aspects of living.

Personality is an important attribute of a person which affects all aspects of one's life. An individual's personality is shaped by many factors such as family, social, peer, religious and socio-economic status. In the academic context, it is essential that students are aware of and understand their personal habits and attitudes which form their initial personality. Personality development is an integral part of one's education. In the process of education from the schooling through the college and university levels, an individual is offered various opportunities such as courses in ethics and values, seminars, workshops, internships, guest lectures to shape his or her individual personality. A winning personality 
is mostly desired by the employers in their prospective employees. There is a close relationship between students having own individual personality and the employment skills which the modern companies demand of the students. It is the responsibility of the students to develop their personality to satisfy the needs of their future employers.

In India, more number of engineering students are unemployed or seeking jobs in different companies different from their subject specialization. Besides a number of reasons, not having a charming and individual personality negatively affects students' personal, academic and professional careers. As the number of unemployed engineering graduates is increasing day by day, the questions to what extent having an individual personality contributes to these engineering students' success in job placements, and how well are the students able to employ these personality traits to perform well in the industry are still a major concern of today's companies. In addition, accreditation of soft-skills is the trend of the modern schools and colleges and they do provide training for students to improve their overall skills including personality development skills required for job placements.

Soft-skills training provides a platform for engineering students to develop their individual personality. Students who have compelling personality with traits such as passion to communicate with people, charisma to be leaders, warmth and humour can easily earn their success in personal, academic, and professional careers. In other words, students' success in life can be attributed their individual personality. Cheng Kai-Wen (2011) in an article, A Study on relationship between Personality traits and Employment factors of College Students states, "in addition to school education, individual personality traits largely affect students' employment" (p.1). But, unfortunately, most engineering students coming from various socio-economic and disadvantaged backgrounds are unaware of the importance and impact of personality on their own career. This lack of understanding creates a gap between what students learn and their aims to finding a good job or a placement. Hence, this study has identified skills and qualities needed by the engineering graduates to enhance their employability.

Soft skills refer to both character traits and interpersonal skills. It is essential for a person to be confident of his/her knowledge and share it with others. It includes the character traits, which are necessary for professional and personal life. In the workplace, soft skills are seen as complementary to hard skills, which refer to a person's professional knowledge and skills. Regardless of academic qualifications and expertise in the field, today's professionals must have a high soft skills quotient to be successful in the competitive era.

On the other hand, the term Employability skills has been given and replaced with other expressions, which differ across continents. It sometimes refers to generic capabilities, transferrable skills, basic skills, essential skills, work skills, soft skills, core skills, core competencies and enabling skills or even key skills. These non-technical skills have been playing an important role for a graduate in getting employed and doing well in the workplace.

The study aims at building engineering students' global personality traits which are required by the employers in the modern context. This study is significant because it bridges the existing gap between the poor personality traits and the required global personality traits. We assume that these engineering students are motivated to improve their personality traits on par with the modern jobs or work places. We also assume that availability and access to modern technology makes engineering students become aware of the importance of honing their personality traits from local to global level. 
In the ESL context, engineering students who come from various socio-economic and disadvantaged backgrounds seem to lack a pleasing personality as an essential physical attribute for achieving success in personal, social, academic, and professional life/careers. Some of the reasons include: students are unaware of the importance of personality for achieving a successful career; students do not have mentors who could motivate their interest towards improving their personality; students do not have good model personalities to emulate in the real life contexts; students lack exposure to global environment; students do not demonstrate attractive personality in interpersonal communication. Absence of charming personality traits acts as a negative force for achieving success in various walks of students' career. In addition, lack of good personality correlates with lack of confidence and good manners. These learners exhibit poor personality traits such as impatience, aggressiveness, and lack of respect, low self-esteem and stress which reflect local context/environment. So there is a perceived gap between the students' current local/poor personality traits and the required global personality traits such as competitive, workobsessed, and achievement-oriented, adaptability, responsibility, compassion and confidence, etc., required by the employers in the present context. Hence, there is a need to build the engineering students' global personality traits in order help them prepare for job placements which would in turn help them in the work environment.

\section{LITERATURE REVIEW}

\section{Personality}

It is an individual's personality that make him or her unique in a given social context. Exhibiting personality traits such as interests, values, skills can affect one's self-image positively or negatively and also informs how others perceive about oneself. According to Rehman (2013), "personality determines a set of important characteristics and how people interact with others. Human personality is the combination of a number of traits. It is important as human to be sociable for instance, the way to communicate and behave in social life" (p.2). According to Matthew et al. (2009), "the structure of personality traits shows consistency across different groups of people in different cultures" (p.153). In other words, there is a close relationship between a person's personality traits and the culture and traditions he or she comes from. Personality, according to George (1992), is "the enduring ways a person has of feeling, thinking, and behaving, is the first determinant of how people think and feel about their jobs or job satisfaction" (p.186)

Allport (1974) described personality as "a dynamic organization within the individual of those psychological systems that determine his unique adjustments to his environment" (cited in Cheng, Kai-Wen, 2011). Robbins (2001) viewed personality as "the sum total of ways in which an individual reacts and interacts with others" (cited in Cheng, Kai-Wen, 2011). Simply put, personality can be defined as a compound of human characteristics and variables. In other words, personality comprises of human characteristics that do not quickly vary and can be used to predict one's short-term behavioral models.

Carver and Scheier (2000) defined personality as "personality is a dynamic organization, inside the person, of psychophysical systems that create a person's characteristic patterns of behavior, thoughts, and feelings" (p.5). In addition to personality traits, Giacalone, Jurkiewicz, \& Promislo, (2015) believes that "an individual's values, beliefs, and culture, are important determinants of perceptions of general well-being" (p.16). 


\section{Soft-skills}

Hurrell et al. (2013) defines soft-skills as "non-technical and not dependent on abstract cognitive, involving interpersonal and intrapersonal skills to expedite controlled performance in certain social contexts" (p.162). Raman and Koka (2015) in a survey to comprehend the significance and requirements of soft-skills in the IT sector found that problem solving skills (98\%), communication skills (92\%), interpersonal skills (88\%), time management skills (65\%) and team building skills (43\%) were top 5 skills among all other skills. In a similar study, Jolly (2012) identified seven skills which are given due importance for graduates' employability - communication skills, critical thinking and problem solving skills, team work, life-long learning and information management skills, entrepreneurship skills, ethics-moral-professional skills, and leadership skills.

Kumar, S and Hsiao, J.K (2005) highlights on engineering education and leadership with incorporating service based learning and problem based learning as important pedagogies to be included in education in the $21^{\text {st }}$ Century. Further, skills such as teambuilding and team cohesion, leadership skills to motivate, inspire and plan, clear understanding of the conceptual skills, strategy execution, values and ethics, communication skills and active listening are given due importance.

Yorke (2006) defines employability as "a set of achievements - skills, understandings and personal attributes - that make graduates more likely to gain employment and be successful in their chosen occupations, which benefits themselves, the workforce, the community and the economy" (p.1). Andreas Blom (2011) in an article, "Employability \& skills set of newly graduated engineers in India" brings up that $64 \%$ of the employers say that they are just somewhat happy with the presentation of the engineering graduates in India. It implies that there is a need for formal pre-placement training among the engineering graduates of India to develop their job related skills. Urvashi Kaushal (2016) states Employability skills is of the opinion that industry specifically looks for graduate engineers who are passionate about their job and who possess employability skills. However, as per the survey by The Hindustan Times, 97\% engineering graduates cannot speak English fluently because they lack English language proficiency (cited in Puranik, 2015).

According to Caten et al. (2019), the significance of soft skills needed for current and future engineers surpasses the significance of the specialized ones such as inventiveness, administration, willingness, versatility and adaptability. Soft-skills are adaptable practices that can be utilized inside a wide scope of capacities, exercises and settings. They are crucial for the work market, explicitly in the profoundly cutthroat situations, and in designing proficient settings is progressively imperative to dominate them along with the hard and specialized abilities (King, 2012).

\section{Entrepreneurial Intention}

The main aim of the study is developing engineering students' personality enriched softskills. The key objectives of the study are -

- to understand students' current personality traits,

- to equip the students with essential personality traits through the soft-skills training

- to improve students' employment readiness personality for better job careers and occupations

\section{Research Questions}

1. Why is building personality important for preparing engineering graduate students for employment readiness? 
2. What is the impact of soft-skills training in building engineering students' personality?

3. Is there any perceived difference in personality traits between the male and female students?

\section{RESEARCH METHODS}

The study was conceptualized and was executed in three phases: phase-1: administered a pre-test; phase-2: designed and conducted soft-skills training; phase-3: administered a posttest and collected students' feedback.

\section{Participants}

All the 25 participants (14 females and 11 males) were studying pre-final year (Third Year) Bachelor of Engineering with the specialization of Electronics and Communication Engineering. They were native speakers of Tamil (regional) language and mostly come from economically and educationally disadvantaged backgrounds. These students have had their schooling and college studies through English as the medium of instruction. These students belong to the age group of 20-21 years and have upper-intermediate level of English proficiency.

\section{Tools}

To understand the students' personality, a pre-test, Humanmetrics Jung Typology Test Questionnaire was administered. This online test was found suitable to understand the participants' personality types.

\section{A Pre-test}

To understand the students' personality, a pre-test, Humanmetrics Jung Typology Test Questionnaire was administered. This online test was found suitable to understand the participants' personality types.

\section{Soft-skills Training}

A 24-hours soft-skills training, two hours of training per day and for the duration of 12 days, for building students' personality was designed and conducted. Topics were carefully selected, teaching schedule was planned, activities like role play, group discussions and mock interviews were employed. Teaching methods such as delivering lectures, doing presentations, showing videos were used. Further, self-learning activities such as video recording of self-introduction, assignments such as preparing resumes were also used. The topics which develop students' personality such as: universal values, drafting resume, corporate etiquette, leadership skills, interview skills, and employability skills were taught in the training. The training incorporated activities to motivate the students to actively engage themselves in each session of the training.

\section{Post-test}

After conducting 24-hours of soft-skills training for two weeks, a post-test, Humanmetrics Jung Typology Test questionnaire, was administered to all the participants. Student feedback was obtained on the relevance and usefulness of soft-skills training.

\section{Data Analysis}

The data were analysed both qualitatively and quantitatively. Qualitative analysis describes the findings, and the quantitative analysis presents the statistical analysis and findings of 
the study through the random sampling statistics method which includes mean, variance, standard deviation, difference, standard error, $\mathrm{t}$-statistic, degree of freedom and $\mathrm{P}$ value.

\section{RESULTS AND DISCUSSION}

\section{Analysis of Pre-test}

In order for enabling the students to achieve their desired job during the placements selection, it was required to understand and analyze their personality in terms of - attitude, confidence, thinking, motivation, perception, emotional intelligence, and current levels of competence for acquiring new skills. Hence, a pre-test was required to classify the participants' personality as: strong, weak, proactive, sensitive, and emotional, etc. Hence, a pre-test was administered online to all the 25 students (14 females and 11 males) to understand their personality types. For this purpose, a personality test based on Carl Jung and Isabel Briggs Myers' typological approach to personality was chosen. The reason for choosing the Myers-Briggs Type Indicator (MBTI) was to know the students' distinct personality traits: Extrovert (E), Introvert (I), iNtuitive (N), Sensing (S), Thinking $(\mathrm{T})$, Feeling (F), Judging (J) and Perceiving (P). The summary of Carl G. Jung's theory of psychological types is presented in table 1 .

Table 1.Summary of Carl G. Jung's theory of psychological types [Jung, 1971]

\begin{tabular}{|l|l|l|}
\hline $\begin{array}{l}\text { People can be } \\
\text { characterized by }\end{array}$ & Personality Type & \multicolumn{1}{|c|}{ Meaning } \\
\hline General attitude & $\begin{array}{l}\text { Extraverted (E) vs. } \\
\text { Introverted (I) }\end{array}$ & $\begin{array}{l}\text { Means that a person derives source of energy and } \\
\text { expression from: - external world, in case of } \\
\text { extravert; - own internal world, in case of introvert. }\end{array}$ \\
\hline Perception & $\begin{array}{l}\text { Sensing (S) vs. } \\
\text { Intuition (N) }\end{array}$ & $\begin{array}{l}\text { Indicates a method by which a person receives } \\
\text { information from: - the external world, in case of } \\
\text { sensing; - the internal or imaginative world, in case } \\
\text { of intuition. }\end{array}$ \\
\hline Judging & $\begin{array}{l}\text { Thinking (T) vs. } \\
\text { Feeling (F) }\end{array}$ & $\begin{array}{l}\text { Signifies how a person processes information and a } \\
\text { decision through: - logic, in case of thinking; - } \\
\text { emotion, in case of feeling. }\end{array}$ \\
\hline Functioning & $\begin{array}{l}\text { Judging (J) vs. } \\
\text { Perceiving (P) }\end{array}$ & $\begin{array}{l}\text { Shows how a person processes information and } \\
\text { implements: - organized and planned, in case of } \\
\text { judging; - improvises and explores alternative } \\
\text { options, in case of perceiving. }\end{array}$ \\
\hline
\end{tabular}

The 4 dichotomies shown in table 1 above yield 16 different combinations, or personality types. Each personality type can be assigned a 4 letter acronym of the corresponding combination of preferences as shown in table 2.

Table 2. Carl G. Jung's 16 different personality types

\begin{tabular}{|l|l|l|}
\hline \multicolumn{2}{|c|}{ The 16 personality types } & \multicolumn{1}{c|}{ Personality defined } \\
\hline$\underline{\underline{\text { ESTJ }}}$ & Extraverted, Sensing, Thinking, Judging & Outspoken, principled, expressive. \\
\hline$\underline{\text { ISTJ }}$ & Introverted, Sensing, Thinking, Judging & Wise and responsible. \\
\hline$\underline{\text { ENTJ }}$ & Extraverted, iNtuitive, Thinking, Judging & Decisive and directed. \\
\hline$\underline{\text { INTJ }}$ & Introverted, iNtuitive, Thinking, Judging & Idea generative and positive. \\
\hline$\underline{\underline{\text { ESTP }}}$ & Extraverted, Sensing, Thinking, Perceiving & Spontaneous and active. \\
\hline$\underline{\underline{\text { STTP }}}$ & Introverted, Sensing, Thinking, Perceiving & Performers, but inactive. \\
\hline$\underline{\text { ENTP }}$ & $\begin{array}{l}\text { Extraverted, iNtuitive, Thinking, } \\
\text { Perceiving }\end{array}$ & $\begin{array}{l}\text { Verbally and cerebrally quick, and love to } \\
\text { argue. }\end{array}$ \\
\hline
\end{tabular}




\begin{tabular}{|l|l|l|}
\hline$\underline{\text { INTP }}$ & Introverted, iNtuitive, Thinking, Perceiving & Pensive, and analytical by nature. \\
\hline ESFJ & Extraverted, Sensing, Feeling, Judging & Entertainers and liberal in giving. \\
\hline$\underline{\text { ISFJ }}$ & Introverted, Sensing, Feeling, Judging & Desire to serve others. \\
\hline$\underline{\text { ENFJ }}$ & Extraverted, iNtuitive, Feeling, Judging & Have charisma to attract people. \\
\hline$\underline{\text { INFJ }}$ & Introverted, iNtuitive, Feeling, Judging & Strongly humanitarian, and are idealists. \\
\hline$\underline{\text { ESFP }}$ & Extraverted, Sensing, Feeling, Perceiving & $\begin{array}{l}\text { Love people, excitement, telling stories } \\
\text { and having fun. }\end{array}$ \\
\hline$\underline{\text { ISFP }}$ & Introverted, Sensing, Feeling, Perceiving & More realistic. \\
\hline$\underline{\text { ENFP }}$ & Extraverted, iNtuitive, Feeling, Perceiving & Friendly and soft-hearted people. \\
\hline$\underline{\underline{I N F P}}$ & Introverted, iNtuitive, Feeling, Perceiving & Live with introverted feeling. \\
\hline
\end{tabular}

The table above shows 16 different personality types and their definitions. This can be used to understand and define students' personality types accurately from the point of view of pre-test and post-test results.

Table 3. Pre-Test Scores of Personality Assessment (Jung + Meyers and Brigs - Online)

\begin{tabular}{|c|c|c|c|}
\hline S.No & Students & Humanmetrics Jung Typology Test & Type \\
\hline 1 & $\mathrm{~S} 1$ & Extravert (56\%), Intuitive (9\%), Feeling (16\%), Judging (34\%) & ENFJ \\
\hline 2 & S2 & Extravert (44\%), Intuitive (25\%), Thinking (16\%), Judging (25\%) & ENTJ \\
\hline 3 & S3 & Introvert (3\%), Intuitive (19\%), Feeling (22\%), Judging (3\%) & INFJ \\
\hline 4 & S4 & Introvert (20\%), Sensing (3\%), Feeling (12\%), Judging (6\%) & ISFJ \\
\hline 5 & S5 & Introvert (31\%), Sensing (6\%), Feeling (3\%), Judging (28\%) & ISFJ \\
\hline 6 & S6 & Extravert (84\%), Intuitive (31\%), Feeling (22\%), Judging (47\%) & ENFJ \\
\hline 7 & S7 & Extravert (25\%), Intuitive (12\%), Thinking (34\%), Judging (9\%) & ENTJ \\
\hline 8 & S8 & Introvert (6\%), Sensing (3\%), Feeling (3\%), Judging (16\%) & ISFJ \\
\hline 9 & S9 & Extravert (19\%), Intuitive (6\%), Thinking (9\%), Judging (44\%) & ENTJ \\
\hline 10 & S10 & Extravert (12\%), Intuitive (12\%), Thinking (12\%), Judging (3\%) & ENTJ \\
\hline 11 & S11 & Extravert (22\%), Sensing (12\%), Feeling (3\%), Perceiving (3\%) & ESFP \\
\hline 12 & S12 & Extravert (84\%), Intuitive (31\%), Feeling (22\%), Judging (47\%) & ENFJ \\
\hline 13 & S13 & Introvert (6\%), Sensing (1\%), Feeling (16\%), Judging (9\%) & ISFJ \\
\hline 14 & S14 & Extravert (28\%), Intuitive (44\%), Feeling (16\%), Judging (50\%) & ENFJ \\
\hline 15 & S15 & Extravert (12\%), Intuitive (3\%), Feeling (6\%), Judging (9\%) & ENFJ \\
\hline 16 & S16 & Extravert (16\%), Intuitive (28\%), Thinking (9\%), Judging (47\%) & ENTJ \\
\hline 17 & S17 & Extravert (9\%), Intuitive (12\%), Feeling (12\%), Perceiving (3\%) & ENFP \\
\hline 18 & S18 & Extravert (3\%), Sensing (3\%), Feeling (19\%), Judging (9\%) & ESFJ \\
\hline 19 & S19 & Extravert (44\%), Intuitive (34\%), Feeling (6\%), Judging (12\%) & ENFJ \\
\hline 20 & S20 & Extravert (31\%), Intuitive (19\%), Feeling (6\%), Judging (9\%) & ENFJ \\
\hline 21 & S21 & Extravert (9\%), Intuitive (44\%), Feeling (6\%), Judging (31\%) & ENFJ \\
\hline 22 & S22 & Extravert (41\%), Sensing (3\%), Feeling (9\%), Perceiving (31\%) & ESFP \\
\hline 23 & S23 & Introvert (19\%), Sensing (1\%), Feeling (19\%), Judging (44\%) & ISFJ \\
\hline 24 & S24 & Extravert (34\%), Intuitive (34\%), Thinking (41\%), Judging (44\%) & ENTJ \\
\hline 25 & S25 & Extravert (12\%), Sensing (1\%), Feeling (19\%), Judging (25\%) & ESFJ \\
\hline
\end{tabular}

The results of the pre-test in table 3 above helps in categorizing the individuals' behavioural patterns. The results indicate that a majority of students -8 students (S1, S6, S12, S14, S15, S19, S20, S21) come under the Extravert, Intuitive, Feeling, and Judging (ENFJ) personality type who have charisma to attract people; 6 students (S2, S7, 
S9, S10, S16, S24) come under the Extravert, Intuitive, Thinking, and Judging (ENTJ) personality type who are decisive and directed by nature; and 5 students (S4, S5, S8, S13, S23) come under the Introvert, Sensing, Feeling, and Judging (ISFJ) personality type who have a desire to serve others. From these personality types (ENFJ, ENTJ, and ISFJ) of 19 students, we can see that these students' current personality traits are closely related. This could be because of the reason that they all share a common socio-economic and educational backgrounds. It implies that students who share common backgrounds also seem to have common personality traits.

The pre-test result also shows that the participants' personality is high in the behaviours as: Extravert, Intuitive, Feeling, and Judging (ENFJ); Extravert, Intuitive, Thinking, and Judging (ENTJ); and Introvert, Sensing, Feeling, and Judging (ISFJ). However, in the present modern context, students with these current personality traits do not seem to attract desired jobs under the career placements. On the other hand, students with personality traits such as: enthusiasm, critical thinking, decision making skills, analytical skills and flexibility are preferred by the employers.

The pre-test helped in identifying and understanding the participants' personality in terms of their behavioral patterns, thought processes, and emotional state of being. This has provided the context for soft-skills training for building students' personality traits. Based on the outcome of pre-test, the participants were given appropriate soft-skills training to improve upon their current personality which was required for their placements.

\section{Analysis and results of Soft-skills Training}

The twelve-day soft-skills training, a total of 24-hours, two hours per day, for building personality was aimed at preparing students for desired jobs under the placements. The purpose of the soft-skills training was to enable students' employability readiness personality which would help in the work environment. The participants of the study were the native speakers of Tamil (regional) language, and belonged to socio-economically and educationally disadvantaged backgrounds.

The training adopted teaching methods such as lectures, interactions, group work, projects, role plays, quizzes, class tests, and various other participatory take home activities. It was observed that students were much interactive throughout the training. As a result, the students absorbed the personality skills and attributes in a gradual manner. The emphasis was given on the self-learning and self-assessment of personality on day-to-day basis. Consequently, students' self-assessment made them become more conscious about their habits and personality in their communication which ensured the skills and attributes learned became part of their personality.

Training in soft-skills provided students with ample support and materials for all the participants to enhance their analytical skills and critical thinking skills which are essential traits of an individual personality and which are specially required in the work /social environment. In addition, soft-skills training provided students with a solid theoretical as well as practical base for building, developing, and managing their personality. The training had positively developed students' overall personality traits such as: selfconfidence, positive attitude, effective communication skills, problem solving skills, emotional intelligence, flexibility, critical thinking, and empathy. Further, this training included career visioning and planning, effective resume writing which are essential for getting jobs during the campus placements. It was found that the training had a positive impact on the students' career prospects.

A special curriculum was designed for incorporating personality development. The training module covered the following topics: 
Table 4. Topics of Soft-skills Training

\begin{tabular}{|l|l|}
\hline \multicolumn{1}{|c|}{ Module } & \multicolumn{1}{c|}{ Topics } \\
\hline Day-1 & $\begin{array}{l}\text { Pre Test - Myers-Briggs-Personality Online } \\
\text { Ice breaker session with activity }\end{array}$ \\
\hline Day-2 & Understanding Universal Human Values, Discipline, Professionalism etc. \\
\hline Day-3 & Developing Problem solving and Critical Thinking Abilities \\
\hline Day-4 & Emotional Intelligence \& Stress Management \\
\hline Day-5 & Managing Effective Interpersonal Relationships, the ability to communicate \\
\hline Day-6 & Personal hygiene-Grooming-Fitness-Nutrition \& Diet \\
\hline Day-7 & $\begin{array}{l}\text { Creativity and Innovation, Assertiveness } \\
\text { Essential attitudinal changes - From a hot head to a cool cucumber and Art of } \\
\text { saying "No" } \\
\text { Perseverance } \\
\text { Openness }\end{array}$ \\
\hline Day-9 & $\begin{array}{l}\text { Communication, Corporate, Dining, workplace and Meeting Etiquette and } \\
\text { Table Manners }\end{array}$ \\
\hline Day-10 & $\begin{array}{l}\text { Positive attitude and Personality development } \\
\text { Unfidence building } \\
\text { Interpersonal Communication }\end{array}$ \\
\hline Day-11 & $\begin{array}{l}\text { Self -Efficiency and Staying Motivation } \\
\text { Language refinement } \\
\text { Post- test Myers-Briggs-Personality online } \\
\text { Feedback }\end{array}$ \\
\hline Day-12
\end{tabular}

The training adopted group discussions and interviews method to develop students' personality traits. The training benefited the students in a number of ways to improve their overall personality. First, the students understood that values influence human personality and values are part of a charming personality. Second, the students exposed to the knowledge of analytical and conflict management skills and they found these skills useful while appearing for campus job placement interviews. Third, students were deeply motivated and improved in personal grooming including appropriate body language in professional and personal communication. Next, students showed acceptable aspects of etiquette and manners in social contexts. Finally, the students were made aware of the importance of having personality traits such as: positive attitude, self-confidence, selfmotivation, critical thinking, adaptability, and acceptance for a successful personal, academic, and professional careers.

The other notable outcomes of the training were that the students developed - a positive attitude towards self and others, self-analysis of attitudes, an understanding of manners and etiquette for work place, self-esteem, leadership qualities, group communication and interview skills, and self-introduction skills. These training imparted personality traits which benefited the students both in their early professional careers, and in their social interactions in the business contexts.

\section{Training Feedback}

A feedback on the usefulness and learning aspects was collected at the end of the training. The participants stated that they found the training useful. They said that they learned and imbibed the personal and professional values taught in the training. They also said that they found the training given was useful during the process of job placements. The majority of the students felt that offline training would have been more useful than the 
online as the interactions between the students and trainer were limited. The students stated that all the sessions were professionally engaging and educating. The students felt that they could identify the development of positive attitude in them after attending the training.

\section{Analysis and results of Post-test}

Table 5. Post-Test Scores of Personality Assessment (Jung + Meyers and Brigs - Online)

\begin{tabular}{|c|c|c|c|}
\hline S.No & Students & Humanmetrics Jung Typology Test & Type \\
\hline 1 & S1 & Extravert (45\%), Intuitive (28\%), Feeling (16\%), Judging (1\%) & ENFJ \\
\hline 2 & S2 & Extravert (47\%), Intuitive (38\%), Thinking (19\%), Judging (12\%) & ENTJ \\
\hline 3 & S3 & Introvert (6\%), Intuitive (9\%), Feeling (28\%), Judging (6\%) & INFJ \\
\hline 4 & S4 & Introvert (12\%), Intuitive (3\%), Feeling (31\%), Perceiving (9\%) & INFP \\
\hline 5 & S5 & Extravert (12\%), Intuitive (12\%), Feeling (31\%), Judging (1\%) & ENFJ \\
\hline 6 & S6 & Extravert (84\%), Intuitive (38\%), Feeling (9\%), Judging (44\%) & ENFJ \\
\hline 7 & S7 & Extravert (59\%), Intuitive (25\%), Thinking (16\%), Judging (47\%) & ENTJ \\
\hline 8 & S8 & Extravert (1\%), Intuitive (6\%), Thinking (1\%), Perceiving (6\%) & ENTP \\
\hline 9 & S9 & Extravert (19\%), Intuitive (22\%), Feeling (16\%), Judging (28\%) & ENFJ \\
\hline 10 & S10 & Introvert (9\%), Intuitive (31\%), Thinking (1\%), Perceiving (25\%) & INTP \\
\hline 11 & S11 & Extravert (12\%), Sensing (22\%), Feeling (6\%), Judging (3\%) & ESFJ \\
\hline 12 & $\mathrm{~S} 12$ & Introvert (16\%), Intuitive (9\%), Feeling (9\%), Judging (3\%) & INFJ \\
\hline 13 & S13 & Extravert (6\%), Intuitive (3\%), Feeling (6\%), Judging (1\%) & ENFJ \\
\hline 14 & S14 & Extravert (34\%), Intuitive (25\%), Feeling (41\%), Judging (45\%) & ENFJ \\
\hline 15 & $\mathrm{~S} 15$ & Introvert (9\%), Intuitive (9\%), Feeling (6\%), Judging (25\%) & INFJ \\
\hline 16 & S16 & Extravert (27\%), Intuitive (6\%), Thinking (12\%), Judging (50\%) & ENTJ \\
\hline 17 & S17 & Extravert (46\%), Intuitive (20\%), Feeling (3\%), Perceiving (12\%) & ENFP \\
\hline 18 & S18 & Extravert (12\%), Sensing (1\%), Feeling (25\%), Judging (1\%) & ESFJ \\
\hline 19 & S19 & Extravert (38\%), Intuitive (28\%), Feeling (28\%), Judging (6\%) & ENFJ \\
\hline 20 & S20 & Extravert (38\%), Intuitive (16\%), Feeling (25\%), Judging (12\%) & ENFJ \\
\hline 21 & S21 & Introvert (9\%), Intuitive (50\%), Feeling (12\%), Judging (25\%) & INFJ \\
\hline 22 & S22 & Extravert (16\%), Sensing (9\%), Feeling (6\%), Perceiving (19\%) & ESFP \\
\hline 23 & S23 & Extravert (9\%), Intuitive (19\%), Feeling (6\%), Judging (19\%) & ENFJ \\
\hline 24 & S24 & Extravert (91\%), Intuitive (25\%), Thinking (22\%), Judging (56\%) & ENTJ \\
\hline 25 & S25 & Extravert (1\%), Sensing (1\%), Feeling (12\%), Perceiving (12\%) & ESFP \\
\hline
\end{tabular}

The table 5 above shows the score of students' personality traits on the post-test which lead to personality types.

The results indicate that a majority of students -8 students (S1, S5, S6, S13, S14, S19, S20, S23) come under the Extravert, Intuitive, Feeling, and Judging (ENFJ); 4 students (S2, S7, S16, S24) come under the Extravert, Intuitive, Thinking, and Judging (ENTJ). And other students come under INFJ followed by ESFP personality types. Overall, from the results of the post-test it is visible that majority of students have extravert and intuitive (EN) traits followed by the feeling and judging (FJ).

Students' personality types both on the pre-test and post-test were compared to see if there is any significant change in the before and after the training in soft-skills. 
Table 6. Common Personality types between the Pre-test and the Post-test

\begin{tabular}{|l|l|c|c|c|l|}
\hline S.No & Student & $\begin{array}{c}\text { Personality } \\
\text { Type } \\
\text { Pre-test }\end{array}$ & $\begin{array}{c}\text { Personality } \\
\text { Type } \\
\text { Post test }\end{array}$ & $\begin{array}{c}\text { Personality } \\
\text { type }\end{array}$ & \multicolumn{1}{|c|}{ Personality defined } \\
\hline 1 & S1 & ENFJ & ENFJ & Same & Have charisma to attract people. \\
\hline 2 & S2 & ENTJ & ENTJ & Same & Decisive and directed. \\
\hline 3 & S3 & INFJ & INFJ & Same & Strongly humanitarian, and are idealist \\
\hline 4 & S6 & ENFJ & ENFJ & Same & Have charisma to attract people. \\
\hline 5 & S7 & ENTJ & ENTJ & Same & Decisive and directed. \\
\hline 6 & S14 & ENFJ & ENFJ & Same & Have charisma to attract people. \\
\hline 7 & S16 & ENTJ & ENTJ & Same & Decisive and directed. \\
\hline 8 & S17 & ENFP & ENFP & Same & Friendly and soft-hearted people. \\
\hline 9 & S18 & ESFJ & ESFJ & Same & Entertainers and liberal in giving. \\
\hline 10 & S19 & ENFJ & ENFJ & Same & Have charisma to attract people. \\
\hline 11 & S20 & ENFJ & ENFJ & Same & Have charisma to attract people. \\
\hline 12 & S22 & ESFP & ESFP & Same & $\begin{array}{l}\text { Love people, excitement, telling } \\
\text { stories and having fun. }\end{array}$ \\
\hline 13 & S24 & ENTJ & ENTJ & Same & Decisive and directed. \\
\hline
\end{tabular}

The table 6 above shows there are 13 students who exhibited the same common in personality types between the pre-test and the post-test. There are 5 students who have exhibited a common ENFJ - personality type who have charisma to attract people; 4 ENTJ personality type who are decisive and directed by nature; followed by 1 INFJ - personality type who are strongly humanitarian, and idealists by nature; 1 ENFP - personality type who are friendly and soft-hearted people; 1 ESFJ - personality type who are entertainers and liberal in giving; and 1 ESFP personality type who love people, excitement, telling stories and having fun personality types.

Table 7. Statistical Test Analysis

\begin{tabular}{|c|c|c|c|c|c|c|c|c|c|}
\hline & & 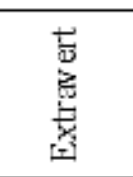 & $\begin{array}{l}\stackrel{D}{\stackrel{D}{\Xi}} \\
\text { 总 }\end{array}$ & 点 & 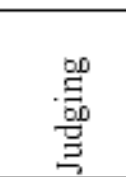 & 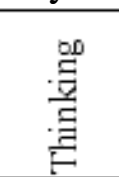 & $\begin{array}{l}\text { 焉 } \\
\text { 量 }\end{array}$ & 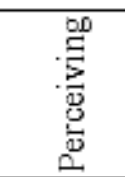 & 茎 \\
\hline \multirow{5}{*}{$\begin{array}{l}\text { Pre } \\
\text { Test }\end{array}$} & Sum & 604 & 363 & 237 & 551 & 121 & 66 & 37 & 33 \\
\hline & count $\mathrm{N}$ & 20 & 16 & 19 & 22 & 6 & 5 & 3 & 9 \\
\hline & Mean & 30.2 & 22.69 & 12.47 & 25.05 & 20.17 & 13.2 & 12.33 & 3.67 \\
\hline & Variance & 507.56 & 159.96 & 46.67 & 279.32 & 159.81 & 114.16 & 174.22 & 10.89 \\
\hline & $\begin{array}{l}\text { Standard } \\
\text { Deviation }\end{array}$ & 22.53 & 12.64 & 6.83 & 16.71 & 12.64 & 10.68 & 13.2 & 3.3 \\
\hline \multirow{5}{*}{$\begin{array}{l}\text { Post } \\
\text { Test }\end{array}$} & Sum & 597 & 422 & 316 & 385 & 71 & 61 & 83 & 33 \\
\hline & count $\mathrm{N}$ & 19 & 21 & 19 & 19 & 6 & 6 & 6 & 4 \\
\hline & Mean & 31.42 & 20.1 & 16.63 & 20.26 & 11.83 & 10.17 & 13.83 & 8.25 \\
\hline & Variance & 650.03 & 156.65 & 121.92 & 356.93 & 67.81 & 9.81 & 40.47 & 73.69 \\
\hline & $\begin{array}{l}\text { Standard } \\
\text { Deviation }\end{array}$ & 25.5 & 12.52 & 11.04 & 18.86 & 8.23 & 3.13 & 6.36 & 8.58 \\
\hline \multicolumn{2}{|c|}{ Difference } & 1.220 & -2.590 & 4.160 & -4.790 & -8.340 & -3.03 & 1.5 & -4.58 \\
\hline \multicolumn{2}{|c|}{ Standard Error } & 7.695 & 4.172 & 2.978 & 5.554 & 6.158 & 4.574 & 6.272 & 3.180 \\
\hline \multicolumn{2}{|c|}{ t-statistic } & 0.159 & -0.621 & 1.397 & -0.862 & -1.354 & -0.668 & 0.239 & -1.44 \\
\hline \multicolumn{2}{|c|}{ Degree of Freedom } & 37 & 35 & 36 & 39 & 10 & 9 & 7 & 11 \\
\hline \multicolumn{2}{|c|}{ P value } & 0.8749 & 0.5387 & 0.171 & 0.393 & 0.205 & 0.521 & 0.8178 & 0.178 \\
\hline
\end{tabular}


Table 7 shows the independent samples t-test that explores the influence of student's personality. The personality has no significant difference in Extravert, Intuitive, Feeling, Judging, Thinking, Introvert and Perceiving determined by the values of $t$ are 0.159 , $0.621,1.397,-0.862,-1.354,-0.668,0.239$ and -1.44 and where the $\mathrm{P}$ values are 0.8749 , $0.5387,0.171,0.393,0.205,0.521,0.8178$ and 0.178 .

Null Hypothesis: There is no significant difference in pre-test and post-test at $5 \%$ level of significance. Alternate Hypothesis: There is significant difference in pre-test and posttest at 5\% level of significance. When the calculated $\mathrm{P}$ value is less than 0.05 , the conclusion is that the two means are significantly different. P-values are always two-sided. Therefore, Null hypothesis is accepted. There is no significant difference in pre-test and post-test at 5\% level of significance. By the statistical test the following results were observed:

Null Hypothesis: Special Training has improved the knowledge level.

Alternate Hypothesis: Special Training has not improved the knowledge level.

In order to identify if there was any significant difference between pre-test and posttest in peer group, paired sample T-test was taken. The following results were derived by -

i. Applying students' $t$-distribution test, we get the calculated value of $t_{C}=1.55$. The table value for Degree of freedom $24, \mathrm{t}_{\mathrm{T}}=2.492$ at $1 \%$ level of significance and $\mathrm{t}_{\mathrm{T}}=1.711$ at $5 \%$ level of significance. Therefore, the calculated value of $\mathrm{t}_{\mathrm{C}}$ less than the table value of $\mathrm{t}_{\mathrm{T}}$ at $1 \%$ and $5 \%$ level of significance. Therefore, null hypothesis accepted. So special training has improved the knowledge level at $1 \%$ and $5 \%$ level of significance.

ii. Applying F- distribution, we get the calculative value of $\mathrm{F}_{\mathrm{C}^{-}}=1.134$. The table value for Degree of freedom $(24,24), \mathrm{F}_{\mathrm{T}}=1.70185$ at $1 \%$ level of significance and $\mathrm{F}_{\mathrm{T}}$ $=1.9838$ at $5 \%$ level of significance.

Therefore, the calculated value of $\mathrm{F}_{\mathrm{C}}$ less than the table value of $\mathrm{F}_{\mathrm{T}}$ at $1 \%$ and $5 \%$ Level of significance. Therefore, null hypothesis accepted. So special training has improved the knowledge level at $1 \%$ and $5 \%$ level of significance.

iii. Applying correlation method, we get correlation value $\mathrm{r}=+0.5324$ (positive correlation). The value of pre-test and post-test move in the same direction. Therefore, special training has improved the knowledge level.

\section{Implications of the Study}

- Students may see various extracurricular and co-curricular activities as opportunities and make use of them for building their personality.

- Students may actively volunteer and participate in various events organized by the college or institute.

- Students may undertake classroom responsibilities to develop their self-esteem, confidence and leadership qualities.

- Students may enrich their positive attitude by analysing their behaviour and personality traits.

- Placement trainers may understand the importance of personality traits of graduates in getting better placements.

- Placement trainers may classify how the students' personality is developing through soft skills training.

- Placement trainers may assist students finding appropriate internships and summer jobs so that students are well aware of the employer expectations. 
- Teachers may identify the teaching strategies which are more effective for their students.

- Teachers may facilitate the students with a better understanding of qualities and skills which the employers value most.

- Teachers may reduce the gap between the new employee abilities and employer expectations by providing students adequate training and exposure to industry.

\section{Limitations of the Study}

This study had the following limitations. One of the limitations of the study was that training was conducted for students only for 24-hours duration over the two weeks. The sample of the study was restricted to only 25 in number which could have been big in size. Training was conducted through online mode which was quite challenging for both the participants as well as the trainers. This virtual training was preferred due to the Covid-19 pandemic situation.

\section{CONCLUSION}

Having and exhibiting good personality traits are essential for students to achieve success in personal, academic and professional careers. Developing personality is a process through various contexts and is a life-long learning process. The present corporate companies recruiting employees who can undoubtedly cope well with other employees of the company. In this context, employers expect that their employees get the work and assignments achieved through appropriate personality.

This study has attempted to help the students build up their individual personality, having identifying and understanding their current personality. It was evident that the training has helped the students developing positive attitude to improving their personality. The training also imparted life skills which would benefit students in their personal life. Moreover, students express that they have equipped themselves with soft-skills and employability skills for getting better job placements.

\section{ACKNOWLEDGEMENTS}

We would like to thank the students who participated in this study and special thanks to the management, Mepco Schlenk Engineering College, Sivakasi for their immense support and encouragement.

\section{REFERENCES}

Ajit, V., \& Deshmukh, P. B. (2013). Factors Impacting Employability Skills of Engineers. International Journal of Science and Research, 2, 30-32.

Allport, G. W. (1974). The Psychology of Participation. Psychological Review, 52, 117-132.

Andreas Blom, H.S. (2011). "Employability \& skills set of newly graduated Engineers in India" World Bank. 1-58.

Briggs Myers, I. (1980, 1995) Gifts Differing: Understanding Personality Type. Palo Alto, Calif: Davies-Black Pub.

Carver, C. S., \& Scheier, M. F. (2000). Perspectives on personality. (4th ed.). Boston, MA: Allyn and Bacon.

Caten, C. S., Silva, D. S., Aguiar, R. B., Filho, L. C. P. S., \& Huerta, J. M. P. (2019). Reshaping Engineering Learning to Promote Innovative Entrepreneurial Behavior. Brazilian Journal of Operations \& Production Management, 16, 141-148. https://doi.org/10.14488/BJOPM.2019.v16.n1.a13 
Cheng Kai-Wen, (2011) A Study on Relationship between Personality Traits and Employment Factors of College Students. Journal of Case Studies in Education. (1) 1-9.

Compton, D. S. (2008). High Reliability Leadership: Developing Executive Leaders for High Reliability Organizations. 376f. Thesis (Doctorate), Ann Arbor: The Faculty of the School of Business of the George Washington University.

De Campos, D. B., de Resende, L. M. M., \& Fagundes, A. B. (2020). The Importance of Soft Skills for the Engineering. Creative Education, 11, 1504-1520. https://doi.org/10.4236/ce.2020.118109

Furler, Katrin \& Gomez, Veronica \& Grob, Alexander. (2013). Personality Similarity andLife Satisfaction in Couples. Journal of Research in Personality. 47(4). 369-375. Doi: 10.1016/j.jrp.2013.03.002.

George, J.M., 1992. The Role of Personality in Organizational Life: Issues and evidence. Journal of Management 18(2) 185-213. Doi:10.1177/014920639201800201

Giacalone, Robert \& Jurkiewicz, Carole \& Promislo, Mark. (2015). Ethics and WellBeing: The Paradoxical Implications of Individual Differences in Ethical Orientation. Journal of Business Ethics. 137. 1-19. Doi: 10.1007/s10551-015-2558-8.

Hurrell A, Scott. Scholarios, Dora \& Thompson, Paul. (2013) "More than a 'humpty dumpty' term: Strengthening the conceptualization of soft skills". Economic Industrial Democracy, 34(1) pp. 161-182.

Itani, M., \& Srour, I. (2015). Engineering Students' Perceptions of Soft Skills, Industry Expectations, and Career Aspirations. Journal of Professional Issues in Engineering Education and Practice, 142, Article ID: 04015005. https://doi.org/10.1061/(ASCE)EI.1943-5541.0000247

Jolly, S.S. (2012). Developing Soft Skills for Enhancing Employability of Engineering Graduates, International Journal of Engineering and Management Research, 2(5) 54-56.

Jung, C.G. (2014). Psychological types - Collected works of C.G. Jung, vol. 6, Princeton UP

Kaushal, U. (2016). Empowering engineering students through employability skills. Higher Learning Research Communications, 6(4), 1-10. Doi: 10.18870/hlrc.v6i4.357

King, C. J. (2012). Restructuring Engineering Education. Journal of Engineering Education, 101 (1), 1-5. Retrieved from http://www.jee.org/2012/January/01

Kumar, S., \& Hsiao, J. K. (2007). Engineers learn "soft skills the hard way": Planting a seed of leadership in engineering classes. Leadership and Management in Engineering, 7(1), 18-23.

Loewe, Nicolas \& Bagherzadeh, Mehdi \& Araya-Castillo, Luis \& Thieme, Claudio \& Batista-Foguet, Joan Manuel. (2014). Life Domain Satisfactions as Predictors of Overall Life Satisfaction Among Workers: Evidence from Chile. Social Indicators Research. 118(1) 71-86. Doi: 10.1007/s11205-013-0408-6.

Nguyen, D. Q. (1998). The essential skills and attributes of an engineer: A comparative study of academics, industry personnel and engineering students. Global Journal of Engineering Education, 2(1), 65-76.

Puranik, A. (2015). 97\% engineering graduates cannot speak English fluently: Survey. Hindustan Times. Retrieved from www.hindustantimes.com/

Raman, M.,\& Koka, A. S. (2015). The Ever-Increasing Demand for Soft Skills at Workplace: A Study on IT Professionals' Perspectives. International Conference on Management and Information Systems. (18), 4-8.

Robbins, S. P. (2001). Organizational Behavior (9th ed.). New Jersey: Prentice-Hall.

Yorke, M. (2006). Employability in Higher Education: What it is - What it is not. York: Higher Education Academy. 1-24. 